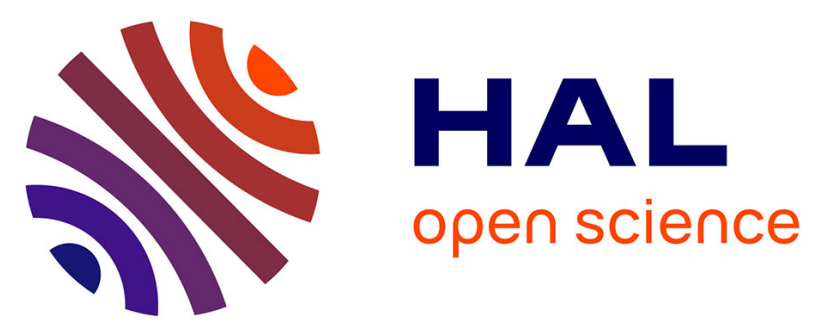

\title{
Genetic variants in BCMO1 and CD36 are associated with plasma lutein concentrations and macular pigment optical density in humans
}

Patrick Borel, Fabien Szabo de Edelenyi, Stéphanie Vincent-Baudry, Christiane Malezet-Desmoulin, Alain Margotat, Bernard Lyan, Jean-Marie Gorrand, Nathalie Meunier, Sophie Drouault-Holowacz, Severine Bieuvelet

\section{To cite this version:}

Patrick Borel, Fabien Szabo de Edelenyi, Stéphanie Vincent-Baudry, Christiane Malezet-Desmoulin, Alain Margotat, et al.. Genetic variants in BCMO1 and CD36 are associated with plasma lutein concentrations and macular pigment optical density in humans. Annals of Medicine, 2011, 43 (1), pp.47 - 59. 10.3109/07853890.2010.531757 . inserm-01478670

\section{HAL Id: inserm-01478670 https://www.hal.inserm.fr/inserm-01478670}

Submitted on 20 Apr 2021

HAL is a multi-disciplinary open access archive for the deposit and dissemination of scientific research documents, whether they are published or not. The documents may come from teaching and research institutions in France or abroad, or from public or private research centers.
L'archive ouverte pluridisciplinaire HAL, est destinée au dépôt et à la diffusion de documents scientifiques de niveau recherche, publiés ou non, émanant des établissements d'enseignement et de recherche français ou étrangers, des laboratoires publics ou privés. 
1 Genetic variants in BCMO1 and CD36 are associated with plasma lutein concentrations and macular pigment optical density in humans.

3

4 Running title: Genes involved in plasma lutein and macular pigment

6 Patrick Borel ${ }^{1,2,3}$, Fabien Szabo de Edelenyi ${ }^{1,2,3}$, Stéphanie Vincent-Baudry ${ }^{4}$, C. Malezet-

7 Desmoulin $^{1,2,3}$, Alain Margotat ${ }^{1,2,3}$, Bernard Lyan ${ }^{5}$, Jean-Marie Gorrand ${ }^{6}$, Nathalie Meunier ${ }^{5}$,

8 Sophie Drouault-Holowacz ${ }^{4}$, Severine Bieuvelet $^{4}$

9

$10{ }^{1}$ INRA, UMR1260 «Nutriments Lipidiques et Prévention des Maladies Métaboliques», F-

1113385 Marseille, France

$12{ }^{2}$ INSERM, ERL U1025, F-13385 Marseille, France

$13{ }^{3}$ Univ Aix-Marseille 1, Univ Aix-Marseille 2, F-13385 Marseille, France

$14{ }^{4}$ Pileje, 75015 Paris, France

$15{ }^{5}$ Centre de Recherche en Nutrition Humaine d'Auvergne, 58 rue Montalembert, 63009

16 Clermont Ferrand Cédex, France

$17{ }^{6}$ Laboratoire de Biophysique sensorielle, Faculté de Médecine, 63001 Clermont-Ferrand,

18 France

20 Corresponding author:

21 Patrick BOREL, Ph.D.

22 UMR 1260 INRA / ERL U1025 INSERM -NLPMM

23 Faculté de Médecine, 27 Boulevard Jean-Moulin, 13385 Marseille Cedex 5, FRANCE.

24 E-mail: Patrick.Borel@univ-amu.fr 


\section{Abstract}

Lutein is recovered at high concentration in the human macula lutea. Recent studies suggest that this micronutrient might be implicated in prevention of age-related macular degeneration. Objective: to identify genes which affect blood and retina lutein concentrations among candidate genes (intestinal sterol transporters and carotenoid oxygenases). Design: a comparative plus an observational study. Participants: Twenty nine healthy subjects for the comparative study and 622 subjects for the observational study. Intervention and methods: All the participants were genotyped for single nucleotide polymorphisms (SNPs) in the candidate genes. Fasting plasma lutein concentrations were measured in all the participants and after six months supplementation, with either a lutein-rich supplement or a placebo, in the 29 subjects who participated in the comparative study. Macular pigment optical density (MPOD), which is a measure of macula concentration of lutein, was measured before and after the dietary intervention in the 29 subjects. Associations between SNPs and plasma lutein and MPOD were assessed by Partial Least Square (PLS) regression followed by univariate analysis. Observed associations between SNPs and plasma lutein were verified by haplotypebased associations analysis in the cohort of 622 subjects. Main outcome measures: plasma lutein levels and MPOD. Results: Six SNPs in four genes (ABCG8, BCMO1, CD36 and NPC1L1) explained 25\% and 38\% of the plasma and MPOD variance, respectively. Subjects with TT at the BCMO1 rs7501331 locus had lower $(P<0.05)$ plasma lutein than CT subjects. Subjects with CC at the CD36 rs13230419 locus had lower $(P<0.05)$ plasma lutein than subjects who carried a T allele. The association between CD36 and plasma lutein was confirmed in the cohort of 622 subjects. Subjects with TT at the BCMO1 rs7501331 locus had a higher $(P<0.05)$ MPOD, and subjects with GG at rs1761667 CD36 locus had a higher $(P<$ 0.05) MPOD than those with an A allele. Conclusions: These results suggest that BCMO1 
51 and CD36 are implicated in plasma and retina concentrations of lutein and that genetic

52 variants in these genes can modulate blood and retina concentrations of lutein.

54 Key words: age-related macular degeneration, bioavailability, carotenoids, eye, genetic

55 variant, genetic polymorphisms, nutrition, retina, xanthophylls

56

57 Key messages: Age-related macular degeneration is an degenerative eye disease that is due, at

58 least in part, to free radicals, and several studies have suggested that antioxidant

59 micronutrients, such as vitamin C, E, carotenoids, and selenium, may participate in the

60 defense of the retina against free radicals. The main carotenoids found in the human retina are

61 the xanthophylls, lutein, zeaxanthin and meso-zeaxanthin. Our results suggest that genetic

62 variants in $\mathrm{BCMO} 1$ and $\mathrm{CD} 36$ modulate plasma and retina lutein concentrations. 
Abbreviations:

65

66 BCMO1: $\beta$-carotene monoxygenase 1

67 BCDO2: $\beta$-carotene dioxygenase 2

68

BMI: body mass index

69

MPOD: macular pigment optical density

70

HPLC: high pressure liquid chromatography

71

PLS: partial least square regression

72

SNP: single nucleotide polymorphisms

73 


\section{Introduction}

Age-related macular degeneration is an degenerative eye disease that is due, at least in part, to free radicals (1). Several studies have suggested that antioxidant micronutrients, such as vitamin C, E, carotenoids, and selenium, may participate in the defense of the retina against free radicals. The main carotenoids found in the human retina are the xanthophylls, lutein, zeaxanthin and meso-zeaxanthin $(2,3)$. Macular meso-zeaxanthin apparently originates from the metabolism of lutein (4), while lutein and zeaxanthin originate from the diet. Lutein and zeaxanthin are mainly obtained from fruits and vegetables. It is assumed that carotenoids are extracted from plant cells in the upper part of the gastrointestinal tract $(5,6)$, solubilized in fat lipid droplets (7) and incorporated into mixed micelles (8). Mixed micelles are assumed to carry carotenoids to the intestinal brush border where they are absorbed by the enterocytes (9). Mechanisms involved in intestinal absorption of carotenoids were initially studied by the Hollander group $(10,11)$. This group concluded that the intestinal absorption of betacarotene, and, by extension, of all the carotenoids, is passive (12). However, this dogma was refuted by recent studies that have shown that absorption of several carotenoids (13-17) involves an enterocyte apical membrane protein, SR-BI (scavenger receptor class B type I), which has been involved in cholesterol uptake. Interestingly, the result obtained in the study dedicated to lutein absorption suggested that other transporters are probably involved (13). We hypothesized that these transporters may be sterol transporters because of the involvement of SR-BI and because they have low substrate specificity. At present, there are several sterol transporters that have been identified: 1) NPC1L1, which is apparently the main protein involved in cholesterol uptake (18) and which has recently been found to be involved in vitamin E uptake (19); 2) SR-BI, which is involved in the uptake of cholesterol (14), carotenoids $(13,14,17)$ and vitamin E (20); 3) ABCG5 and ABCG8, which are involved in 
99

phytosterols and cholesterol efflux back into the intestinal lumen (21) and 4) ABCA1, which

100 is mainly located at the basolateral side of the enterocyte and is involved in cholesterol (22)

101 and tocopherol efflux $(23,24)$.

102

103

104

105

106

107

108

109

110

111

112

113

114

115

116

117

118

119

120

It is assumed that, after absorption, lutein is incorporated into chylomicrons and

transported to the liver. A fraction of lutein is then incorporated into VLDL and distributed to peripheral tissues by lipoproteins (25-27). A recent study has suggested that SR-BI is involved in xanthophyll uptake by retina cells (28). Since the sterol transporters mentioned above are expressed not only in the intestine but also in various other tissues, we hypothesized that they are good candidates for retina uptake of lutein. Finally, it is assumed that BCMO1 ( $\beta$-carotene monoxygenase 1$)$ and/or BCDO2 ( $\beta$-carotene dioxygenase 2$)$, which are involved in cleavage of provitamin A carotenoids in retinal and apo-carotenals, respectively (29), might be involved in the metabolism of lutein and thus in its blood and tissue concentration. This is supported by a recent study showing that a nonsense mutation in BCDO2 was associated with the yellow skin phenotype in sheep, suggesting a broad specificity of this enzyme for carotenoids (30).

The main objective of the present study was to assess whether some sterol transporters and carotene oxygenases are involved in blood and macular concentrations of lutein. To attain our goal, we studied associations between single nucleotide polymorphisms (SNPs) of genes that encode these transporters and the two carotene oxygenases, and blood and macula concentrations of lutein in 29 healthy subjects. Observed associations between genetic variants and plasma lutein were further verified in a cohort of 622 subjects. 


\section{Material and Methods}

123

124

125

126

127

128

129

130

132

133

134

135

136

137

138

139

140

141

142

143

144

145

146 population (36).

\section{Subject number and characteristics}

Since there were no data on the effect of the selected genetic variants on either plasma lutein levels or macular pigment optical density (MPOD), we were unable to perform a power analysis to calculate the number of subjects required to observe a significant effect with an $80 \%$ power. We decided to work with 30 subjects in order to divide the group into two subgroups with 15 subjects each: one took a lutein supplement; the other, a placebo (see the paragraph on lutein supplementation).

Thirty healthy, non-obese males were recruited. They had no disease history, hyperlipemia or hyperglycemia. Their characteristics and daily nutrient intakes are reported in Table 1. One subject withdrew for personal reasons during the study. Twenty-nine of the thirty selected subjects were non-smokers. They were not taking any medication known to affect lutein or lipid metabolism during the month before the study started or during the study period. The study was approved by the regional committee on human experimentation (CPP Sud Est VI, France) and adhered to the tenets of the Declaration of Helsinki. The objectives and requirements of the study were fully explained to the participants, and informed written consent was obtained for each subject. The subjects' usual diet was estimated with a three-day food diary before the study started. Portion sizes were estimated with photographs compiled in a manual adapted from the Su.Vi.Max picture booklet (31). The dietary diary was analyzed for nutrient composition with a diet analyzer software (GENI 6.5; Micro6, Villers les Nancy, France). The software database was extended for carotenoids by mean of the USDA carotenoid food-composition database (32). The lutein intake was close to that previously observed in French group of volunteers (33-35), and close to the intake reported in a US 
Choice of candidate SNPS

Candidate SNPs in genes involved in sterol absorption were selected through an analysis of previous studies describing associations between these SNPs and digestion, transport or metabolism of sterols. The SNP in BCDO2 was advised by Dr George Lietz (Newcastle University, UK) from an unpublished study. Characteristics of the SNPs are presented in Table 2. SNPs were validated for the oligo-ligation assay (SNPlex, see below) by several criteria: 1) genome screening, in which the SNPs may be located in a genome region that is homologous with at least one other genome region, leading to a lack of assay specificity and the potential for spurious ligation templates; 2) assay rules, in which an individual SNP assay cannot be designed due to deleterious sequence contexts or non optimal interactions among the assay components; for example, aspects of the SNP sequence or assay components may result in secondary structure and reduce assay performance, including a series of contiguous Gs or a series of 16 weak contiguous bases (A's or T's) within 25 bases of the SNP and 3) pooling rules, in which deleterious potential interactions may occur between specific SNP assays in the assay pools and false signals may be generated due to components from different assays interacting with genomic DNA.

The SNPs that were not validated for SNPlex were replaced by alternate SNPs, in linkage disequilibrium with the initial SNPs, or analyzed by Taqman (see thereafter).

\section{DNA preparation and genotyping methods}

Genomic DNA was prepared from $2 \mathrm{ml}$ whole blood and purified with the NucleoSpin ${ }^{\circledR}$ Blood L kit ref 740954 (Macherey Nagel, Hoerdt, France). A mean of $15 \mu \mathrm{g}$ of DNA was isolated from each blood sample. The purity and quantity of DNA was checked by spectrophotometry at $260 \mathrm{~nm}$ and $280 \mathrm{~nm}$. A total of $100 \mu \mathrm{l}$ of DNA at a concentration of 10 
$172 \mathrm{ng} / \mu \mathrm{l}$ was added to a plate (Dutscher, Marseille, France) for genotyping. SNPs were

173 genotyped with an oligo-ligation assay (SNPlex, Applied Biosystems, Foster City)(37, 38) or

174 a TaqMan method (Applied Biosystems) following the manufacturers' guidelines.

175 The oligo-ligation assay consists of designing 3' specific primers for each SNP, with

176 two primers carrying the SNP-base specific 3' end and one common primer that starts 5' to

177 the next base in the target sequence. The two allele specific primers carry unique ZIP codes

178 that determine each allele. Primers are annealed to the target sequence according to the

179 manufacturer's recommendations. A ligation reaction will join the allele specific primer with

180 the common primer if the allele specific 3'-base is present. A short fluorescent dye labeled

181 probe, homologous to the ZIP code sequence, is then hybridized to the immobilized product.

182 Up to 48 SNPs can thus be multiplexed into one oligo-ligation reaction. Following the

183 manufacturer's recommendations, genomic DNA was heat fragmented. The allele specific

184 fluorescent probes were separated on an automated sequencer (ABI 3730, Applied

185 Biosystems, Foster City). Alleles were binned and called with the GeneMapper software

186 (Applied Biosystems, Foster City).

187 The TaqMan assays were performed when selected SNPs could not be analyzed by

188 SNPlex. This was the case for two SCARB1 SNPs, rs4238001, and the one called "intron 5".

189 Probes were purchased from the manufacturer and used according to the manufacturer's

190 guidelines. DNA was PCR-amplified by denaturation at $95^{\circ} \mathrm{C}$ for $10 \mathrm{~min}, 40$ cycles at $92^{\circ} \mathrm{C}$

191 for $15 \mathrm{sec}, 60^{\circ} \mathrm{C}$ for $1 \mathrm{~min}$, and $72^{\circ} \mathrm{C}$ for $45 \mathrm{sec}$, followed by elongation at $72^{\circ} \mathrm{C}$ for $5 \mathrm{~min}$.

192 TaqMan assays were then read on a 7900HT Fast Real-Time PCR System (Applied

193 Biosystems), and alleles were called by the SDS software (Applied Biosystems).

194 


\section{Lutein supplementation}

The 29 subjects were first asked to follow a lutein-poor diet for 3 wks. To attain this objective they were asked to discard lutein-rich foods from their usual diet (a list of lutein-rich food was given to the volunteers). The subjects then came to a Center for Clinical Investigation (Centre de Recherche en Nutrition Humaine d'Auvergne) after an overnight fast, and a blood sample was collected. The same day, the subjects also came to a biophysics laboratory to have their MPOD measured (the right eye was used for most of the subjects). Subjects were randomly assigned to one of the two groups. One received a placebo, while the other received a lutein-rich supplement (Visiobane Protect, Pileje, France) for 6 months. The supplement was provided as two pills containing $5 \mathrm{mg}$ of lutein esters each. Subjects were asked to eat the pills during their main meals. The supplement also contains : Porphyra, B vitamins, vitamin $\mathrm{C}$ and $\mathrm{E}$, fish oil, bee wax and gelatine. The placebo contained only refined sunflower oil. At the end of the supplementation period, all the subjects came back to the Center for Clinical Investigation for collection of a second fasting blood sample, and to the biophysics laboratory for another MPOD measurement.

\section{Measurement of macular pigment optical density (MPOD)}

The MPOD was determined as described by the van Norren team $(39,40)$. In summary, the radiant flux of the pattern radiated from photoreceptors at the fovea (sample field: $2 \mathrm{deg}$ ) and the radiant flux of the beam reflected specularly by the ILM in the perifovea (used as reference) were measured. The measuring light was provided by a $75 \mathrm{~W}$ Xenon lamp (Oriel) that was filtered either by an interference filter at $470 \mathrm{~nm}$ (FWHM $10 \mathrm{~nm}$, Oriel), or an interference filter at $532 \mathrm{~nm}(\mathrm{FWHM} 10 \mathrm{~nm}$, Oriel). The retinal illuminances were $4.8 \log \mathrm{Td}$ and $5.5 \log$ Td for the blue and green lights, respectively. The distribution of light in the pupil was measured with a CCD camera cooled by liquid nitrogen (Princeton Instruments). This 
222

223

224

225

camera had a resolution of $512 \times 512$ pixels, with an image depth of 16 bits. The pixel size in the pupil was $0.0255 \mathrm{~mm}$. We combined areas of $2 \times 2$ pixels, giving a resolution of 0.051 $\mathrm{mm} /$ pixel. Two stepping motors $\mathrm{X}$ and $\mathrm{Y}$ (Newport) allowed the center $\mathbf{J}$ of the entrance pupil (dia $0.2 \mathrm{~mm}$ ) to be positioned at the chosen location in the eye's pupil. The head of the subject was stabilised by a bite bar which was fixed on a three-dimensional positioner. The main optical components were mounted on a single plate which could be shifted longitudinally, thus allowing focus adjustment from -12 diopters to +12 diopters of ametropia. The pupil was dilated by application of $0.5 \%$ Mydriacyl to a minimum diameter of $7 \mathrm{~mm}$. The eye was then aligned to the reflectometer. A fixation target was used to direct the subject's gaze either to the center of the sampling area or at a site 6 deg temporal to the fovea. At the fovea the center $\mathrm{J}$ of the entrance pupil was aligned to photoreceptor axes. At 6 deg eccentricity, the point $\mathrm{J}$ was positioned at the center of the eye's pupil. For each of these retinal eccentricities, the measuring green beam bleached the retina for a period of $15 \mathrm{~s}$, then three pupil images were captured at $532 \mathrm{~nm}$ (integration time of $4 \mathrm{~s}$ ), with an interval of $10 \mathrm{~s}$ between each one; they were followed by three pupil images at $470 \mathrm{~nm}$.

\section{Plasma lutein extraction and HPLC analysis of lutein}

Plasma lutein was extracted and analyzed as previously described (41). Briefly, 200

$\mu \mathrm{L}$ of plasma was deproteinized by adding one volume of ethanol containing the carotenoid echinenone (as an internal standard). Lutein was extracted twice by the addition of two volumes of hexane. The hexane phases obtained after centrifugation $\left(500 \mathrm{~g}, 10 \mathrm{~min}, 4^{\circ} \mathrm{C}\right)$ were pooled and evaporated completely under nitrogen. The dried extract was dissolved in $200 \mu \mathrm{L}$ of dichloromethane/methanol mixture (65/35; V/V). All extractions were performed at room temperature under yellow light to minimize light-induced damage. A volume of $80 \mu \mathrm{L}$ was used for HPLC analysis. The HPLC system consisted of a 150 X $4.6 \mathrm{~mm}, \mathrm{RP} \mathrm{C}_{18}, 3-\mu \mathrm{m}$ 
247 Nucleosil column (Interchim, Montluçon, France) coupled with a 250 X 4.6 mm RP C $18,5-$

$248 \mu \mathrm{m}$ VydacTP 54 column (Hesperia, CA) and a 10 X 4.6 mm RP $\mathrm{C}_{18}, 5-\mu \mathrm{m}$ hypersil guard

249 column. The mobile phase consisted of acetonitrile/methanol containing $50 \mathrm{mmol} / \mathrm{L}$

250 ammonium acetate/water/dichloromethane (70/15/5/10; V/V/V/V). Solvents were HPLC

251 grade from Carlo Erba - SDS (Peypin, France). The flow rate was $2 \mathrm{~mL} / \mathrm{min}$. The columns

252 were kept at a constant temperature $\left(30^{\circ} \mathrm{C}\right)$. The HPLC system consisted of a Waters system

253 equipped with a UV-visible photodiode-array detector (Waters 996). Carotenoids were

254 detected at $450 \mathrm{~nm}$ and identified by their retention time compared with pure (>95\%)

255 standards. Quantifications were performed with Millennium 32 software (version 3.05.01),

256 comparing peak area with carotenoid standard reference curves. Carotenoid standards were a

257 generous gift of DSM LTD, Basel, Switzerland.

Plasma lipids and apolipoproteins

Triglyceride and total cholesterol concentrations were determined by enzymatic

261 procedures with commercial kits (Roche, Switzerland). High-density lipoprotein (HDL)

262 cholesterol was measured after sodium phosphotungstate-magnesium chloride precipitation.

263 Low-density lipoprotein (LDL) cholesterol was estimated indirectly by use of the Friedewald 264 formula.

Characteristics of the cohort of 622 subjects

In order to verify the associations observed in the study on 29 volunteers we decided

268 to verify associations observed between genetic variants and plasma lutein on a cohort of 622

269 french subjects. This cohort was a subset of the french SUVIMAX cohort (42). Characteristics

270 of this cohort were as follow: 281 males and 341 females, $61.65 \pm 0.25$ years old, BMI: 25.76

$271 \pm 0.17 \mathrm{Kg} / \mathrm{m} 2$, plasma cholesterol: $2.23 \pm 0.01 \mathrm{~g} / \mathrm{l}$, plasma lutein: $540 \pm 10 \mathrm{nmol} / \mathrm{L}$. Subjects 
272 were genotyped for SNPs in CD36 and BCMO1 and haplotype effects of these genes on

273 plasma lutein were tested.

Statistical analysis

As a first approach, we wanted to estimate the relationships between genotypes, and

277 both plasma lutein and MPOD in the study on 29 volunteers. For this purpose, we used partial

278 least square (PLS) regression. PLS regression was performed by the SIMCA-P software,

279 version 11.0 (Umetrics, Umeå, Sweden). The Y matrix was composed of the 2 vectors

280 containing the initial plasma lutein concentrations and the initial MPOD. The X matrix

281 contained the genotypes for the 20 SNPs. The values in the Y matrix were scaled with a unit

282 variance scaling prior to the calculation of the latent vectors. After examination of the

283 importance of each dependent variable, it appeared that only six SNPs were significant for the

284 regression model. Therefore, a second regression, which used the genotypes from these six

285 SNPs in the X matrix, was performed in order to minimize the noise in the model. The PLS

286 model was calculated with the function "autofit" in the SIMCA-P software in order to find the

287 optimal number of latent vectors. Note that correction for multiple testing was not compulsory

288 with PLS regression because independent variables are not treated independently but are used

289 simultaneously to find a reduced number of latent variables for the model. Furthermore,

290 model validation, testing for the robustness of the model and its generalization to new data, is

291 performed in this model with cross-validation.

292 In a second approach, we performed univariate statistical analyses only in associations

293 that were simultaneously significantly associated with the two independent markers of lutein

294 metabolism, which were plasma lutein and MPOD. The independence of these two

295 parameters was checked by assessing the relationship between them (lack of linear Pearson's

296 correlation). The fact that SNPs were found associated with two independent markers of 
297 lutein metabolism by both PLS and univariate analysis reduces the risk of false positive

298 associations. Differences between means obtained in the different genotype groups were

299 analyzed either by ANOVA followed by the post hoc Tukey-Kramer test, or by the Student's

300 t-test when only two genotypes were observed. Values of $\mathrm{p}<0.05$ were considered

301 significant. All univariate statistical analyses were performed with Statview software version

3025.0 (SAS Institute, Cary, NC, U.S.A.).

303 In a third approach we performed an haplotype-based association analysis of data

304 which originated from a cohort of 622 french subjects (see above the characteristic of the

305 subjects). This analysis was performed with the THESIAS software, which is based on the

306 Stochastic-EM algorithm, and which allows to infer haplotypes from genotypic data and to

307 test their associations with phenotypes of interest (43). Analysis were performed after

308 adjustement for the following covariables: gender, age and BMI. 


\section{Results}

Effect of dietary intervention on dietary lutein intake

Dietary lutein intake of the subjects, fell from $1.3 \mathrm{mg} / \mathrm{d}$ to $0.03 \mathrm{mg} / \mathrm{d}$ after the lutein

314 poor diet, showing a good compliance of the subjects to the recommendations, and increased

315 to $0.4 \mathrm{mg} / \mathrm{d}$ during the dietary intervention, which was probably due to the fact that this period

316 occurred during spring where mots subjects increase their intake of fruits and vegetables rich

317 in lutein. Note that there was no significant difference between the intake of the two groups at 318 any of these periods..

Effect of the dietary intervention on plasma lutein concentrations

Initial plasma lutein concentrations ranged between 110 and $470 \mathrm{nmol} / \mathrm{L}(290 \pm 20$

$\mathrm{nmol} / \mathrm{L})$. This high interindividual variability $(\mathrm{CV}=32 \%)$ did not change when plasma lutein

was corrected for plasma cholesterol $(\mathrm{CV}=36 \%)$, nor when it was corrected for

lutein+zeaxanthin intake $(\mathrm{CV}=146 \%)$. Surprisingly, the group that took the placebo (placebo group) exhibited a significant $(P<0.05)$ rise in plasma lutein concentration after the dietary intervention (Figure 1A). Nevertheless, this increase was much higher in the group that took lutein supplement $(+143 \%)$ than in the placebo group (+77\%). Individual plasma lutein responses to the placebo and the lutein supplement are shown in Figure 1B and 1C,

respectively. The interindividual response (change from the initial value) strongly varied, ranging from -100 to $1140 \mathrm{nmol} / \mathrm{L}$. Consequently, the interindividual variability in plasma

331 lutein increased after lutein supplementation $(\mathrm{CV}=29 \%$ and $56 \%$ before and after supplementation, respectively). 
335 plasma lutein for plasma cholesterol. This adjustment led to observe a significant increase $(P$

$336=0.003$ ) in the plasma lutein/cholesterol ratio after lutein supplementation and no significant

337 increase $(P=0.067)$ of this ratio after supplementation by the placebo (data not shown).

Relationships between genetic variants and biomarkers of lutein status

The PLS analysis showed that the best model to explain the variance of both plasma

341 lutein and MPOD was the one with one latent vector only. This model explained $31.4 \%$ of the

342 variance of the Y matrix (38.1\% for MPOD and $25.1 \%$ for plasma lutein). The predictive

343 value of the model was estimated after cross-validation. We obtained an estimated variation

344 of Y explained by the model of $16.1 \%$ (14.6\% for MPOD and $18.3 \%$ for plasma lutein). The

345 six SNPs selected by the regression model were found in four genes: BCMO1, CD36,

346 ABCG8 and NPC1L1. Coefficients of NPC1L1 were, however, not statistically significant.

347 Furthermore, only the SNP in BCMO1 and two SNPs in CD36 were simultaneously

348 significantly related to the two independent markers of lutein status. Thus association studies

349 described thereafter were performed only with these two genes.

Associations between genetic variants and plasma lutein levels

Univariate analysis of plasma lutein showed that this parameter was higher in subjects

353 who carried the CT genotype at BCMO1 rs7501331 than in those who carried the TT

354 genotype (Figure 2A), although the difference was not significant. Note that no subject

355 homozygous for the $\mathrm{C}$ allele was found in the study cohort. The difference became significant $356(P=0.022)$ when plasma lutein was corrected for plasma cholesterol: $+33 \%$ in the subjects 357 with the CT genotype (Figure 2B). Finally, no significant difference was observed when 358 plasma lutein was corrected for lutein intake (data not shown). 
Univariate analysis also showed that subjects with the CC genotype at rs13230419, a

360 CD36 locus) had lower plasma lutein $(P=0.014)$ than subjects with a $\mathrm{T}$ allele at this locus

361 (Figure 3A). The difference remained significant $(P=0.044)$ when plasma lutein was

362 corrected for plasma cholesterol (Figure 3B). Adjustment for lutein intake led to a

363 comparable figure (data not shown).

364 Tables 3 and $\mathbf{4}$ show results of haplotypes association analysis between BCMO1 and

365 CD36 haplotypes and plasma lutein/zeaxanthin concentration in a cohort of 622 subjects.

366 There was no significant effect of the BCMO1 haplotypes on plasma lutein, either adjusted or

367 not for plasma cholesterol (Table 3). Conversely, a minor haplotype of CD36 (AGA) had a

368 significant effect on plasma lutein/zeaxanthin concentrations as compared to the most frequent

369 haplotype (AAG). Note that this effect remained significant $(P=0.048)$ when plasma

370 lutein/zeaxanthin was adjusted for plasma cholesterol (data not shown).

Effect of the dietary intervention on $M P O D$

MPOD measured before supplementation was not significantly different between the

374 two groups (Figure 4A). After the supplementation period, MPOD significantly increased $(P$ $375<0.05)$ in both groups. Again, this increase was higher in the lutein group $(+22 \%)$ than in the 376 placebo group $(+11 \%)$ (Figure 4A). Interestingly the interindividual variability in initial

377 MPOD $(\mathrm{CV}=32 \%$, Figure 4B) was similar to that observed for plasma lutein and, as observed

378 for plasma lutein, increased when MPOD was corrected for lutein intake (CV=142\%).

379 Conversely, in opposite to what was observed for plasma lutein, the interindividual variability 380 in MPOD decreased after supplementation with lutein (CV decreased from $39 \%$ to $25 \%$, 381 Figure 4B).

Figure 5A shows that the MPOD response was not related to the plasma lutein 383 response. Furthermore, the initial MPOD was not related to the initial plasma lutein $(\mathrm{r}=$ 
$3840.009, P=0.96)$, when either corrected or not for plasma cholesterol $(\mathrm{r}=0.20, P=0.30)($ data

385 not shown). Conversely, there was a significant inverse relationship between the MPOD

386 response and the initial MPOD (Figure 5B). In other words, the lower the initial MPOD was,

387 the higher the MPOD response to the dietary intervention.

Association between genetic variants and MPOD

$390 \quad$ Figure 6 shows results of univariate analysis between the SNPs in BCMO1 and CD36 391 and the initial MPOD. Subjects with CT at the BCMO1 SNP had significantly lower initial 392 MPOD values than homozygous TT (Figure 6A). Interestingly the CT subjects had a higher 393 MPOD response (delta from initial values) to the lutein supplement than the TT subjects (data 394 not shown). Subjects bearing an A allele at rs1761667 (a CD36 locus) had significantly lower 395 MPOD than homozygous GG (Figure 7B). As observed for BCMO1, the genetic groups with 396 the lower MPOD (the AA and AG groups) had a higher MPOD response to the lutein 397 supplement than the group with the higher MPOD (the GG group) (data not shown). 398 


\section{Discussion}

Initially, we verified the effect of lutein supplementation on two markers of lutein status, which were plasma lutein and MPOD. The dose of lutein provided by the supplement $(10 \mathrm{mg} / \mathrm{d})$ and the duration of the supplementation (6 months) were selected to enable the detection of significant variations in MPOD (44-46). The fact that, for better compliance, lutein was provided as pills instead of foods (spinach, for example) is unlikely to have influenced the results significantly, because it has been shown that lutein bioavailability is not significantly different between spinach and lutein supplements $(47,48)$. The significant increase of both markers in the lutein supplemented group was expected, because it is in agreement with previous studies $(44,48,49)$. The first obvious conclusion is that these increases were due to the lutein present in the supplement. The significant increase of both markers in the placebo (control) group did, however, raise some questions about this conclusion. Nevertheless, it should be remembered that lutein was not only provided by the supplement, but it was also, of necessity, present in the subjects' diets. We thus hypothesized that the increase of the lutein markers in the placebo group was due to an increase in dietary lutein intake. This hypothesis was supported by the fact that a second food diary, kept during the supplementation period, which occurred in spring where subjects increase their intake of lutein-rich fruit and vegetables, showed that all subjects increased their dietary intake of lutein as compared to their initial dietary intake. Given that the food diaries showed that the dietary intake of lutein during the supplementation period was not significantly different between the two groups, this demonstrated that the higher increase of both markers in the lutein supplemented group (+143\% vs. $+77 \%$ for plasma lutein and $+22 \%$ vs. $+11 \%$ for MPOD, in the lutein and placebo groups, respectively) was due to the lutein supplement. 
MPOD is assumed to be related to the macula lutea concentration of lutein. Because

424 some studies showed a significant relationship between blood lutein and MPOD $(36,50)$,

425 while other studies did not find this association $(49,51)$, we aimed to re-assess this

426 relationship. Our results show that MPOD was not related to plasma lutein, whatever the

427 parameter used, such as plasma lutein, plasma lutein corrected for plasma cholesterol or

428 plasma lutein corrected for lutein intake. In fact, this association, when observed, was weak

429 and found only with a large number of subjects $(36,52)$. Thus, considering the small number

430 of subjects in our study, our result is not surprising. Interestingly, and in agreement with a

431 recent study (53), we found that the MPOD response was inversely and significantly related to

432 the initial MPOD. This shows that the subjects who respond the most to dietary lutein are

433 those who have the lowest initial MPOD. This should be taken into account in future studies

434 of the effect of different parameters on MPOD.

435 The main objective of this study was to check the hypothesis that genetic variants can

436 explain, at least in part, the interindividual variability in blood lutein concentrations and

437 MPOD observed in this study (figures 1 and 5), as well as in previous studies. To that aim, we

438 compared plasma lutein concentrations and MPOD in volunteers bearing different SNPs in

439 genes potentially involved in lutein metabolism. Because we wanted to predict blood lutein

440 concentrations and MPOD (dependent variables) from a large set of SNPs (independent

441 variable), we used PLS regression. As stated in the material and method section this analysis

442 has the advantage of avoiding false positive results that could be obtained in multiple testing

443 and small sample size. This analysis showed that a significant part of the variability (38\% for

444 MPOD and 25\% for plasma lutein) can be assigned to genetic variants in CD36, BCMO1 and

445 ABCG8. Furthermore, three SNPs were simultaneously and significantly related to plasma

446 lutein and MPOD: one in BCMO1, and two in CD36. Since plasma lutein and MPOD were

447 not related, this double association further supports the involvment of these genes in lutein 
448 metabolism. However, in order to reinforce the validity of these associations we decided to

449 perform an haplotype-based association analysis of data which originated from a cohort of

450622 subjects. This analysis confirmed the association of plasma lutein with CD36 but failed to

451 find a significant association between plasma lutein and BCMO1. This is likely due to an

452 insufficient statistical power because a recent genome wide association study supported a role

453 of BCMO1 in plasma lutein levels (54).

454 The association of plasma lutein concentration with BCMO1 suggests that this gene,

455 which encodes an enzyme responsible for the cleavage of provitamin A carotenoids into

456 retinal (29), is also involved in the metabolism of lutein, which is not a provitamin A

457 carotenoid. This association is probably indirect because zeaxanthin (a xanthophyll which

458 exhibits a chemical structure very close to lutein) was not cleaved in vitro by BCMO1 (55),

459 supporting the assumption that BCMO1 is not involved in lutein cleavage. One hypothesis

460 might be that vitamin A status, related to BCMO1 activity, can modulate lutein metabolism

461 by modulating expression of transporters of lutein. This is supported by a publication showing

462 that all-trans retinoic acid strongly up-regulate CD36 (56). The association between BCMO1

463 and MPOD was observed for the first time and suggests that BCMO1 activity modulate the

464 concentration of lutein in the retina. The effect of this SNP in BCMO1 on plasma and retina

465 concentration of lutein is probably related to an effect on BCMO1 activity. Indeed this SNP

466 leads to a change in an amino acid (A379V), and this change is functional, as a recombinant

$467267 \mathrm{~S}+379 \mathrm{~V}$ double mutant showed a reduced BCMO1 catalytic activity and carriers of the

$468379 \mathrm{~V}$ genotype had a reduced ability to convert $\beta$-carotene (57).

469 The second gene that is apparently involved in lutein metabolism is the scavenger

470 receptor CD36, also known as FAT. This is not very surprising as, SR-BI, a scavenger

471 receptor like CD36, has been involved in the uptake of lutein by both intestinal (13) and

472 retinal cells (28). Because CD36 is expressed in the intestine and in several other tissues, we 
473 hypothesize that functional variants in its gene may affect lutein absorption efficiency, or

474 tissue uptake of lutein, or both, leading to lower concentrations of plasma and retina lutein.

475 Unfortunately, there are no functional data available about the effect of the studied variants in 476 CD36 on the activity, or expression, of CD36.

477 The lack of association between the two lutein biomarkers and the SNPs in SCARB1, 478 the gene that encodes SR-BI, was rather unexpected, since this transporter has been involved 479 in lutein absorption (13) and retinal cell uptake (28). Furthermore, two out of the three 480 genotyped SNPs (rs5888 and rs4238001) have been associated with lower SR-BI protein 481 expression and function $(58,59)$. Thus, the lack of association between these SNPs and 482 plasma lutein and MPOD, together with the fact that CD36 (another scavenger receptor which 483 share many structural characteristics with SR-BI) was associated with plasma and retina 484 lutein, suggests that CD36 is probably more important for lutein uptake by cells than SR-BI 485 and that it can compensate for lower expression/function of SR-BI. The fact that two genes were associated with the studied biomarkers of lutein status 487 raises questions about interactions between these genes. Unfortunately, the number of subjects 488 enrolled in this study was too low to detect a significant interaction between BCMO1 and 489 CD36 (two factors ANOVA). In summary, our results suggest that genetic variants in BCMO1 and CD36 modulate

492 plasma and retina lutein concentrations. This observation may have consequences with regard 493 to the recommended dietary intake of lutein in groups of subjects bearing unfavourable 494 genetic variants in these genes. 


\section{References}

497 1. Evans JR. Risk factors for age-related macular degeneration. Prog Retin Eye Res. 2001 Mar;20(2):227-53.

498 2. Krinsky NI, Landrum JT, Bone RA. Biologic mechanisms of the protective role of lutein and zeaxanthin in 499 the eye. Annu Rev Nutr. 2003;23:171-201.

500 3. Landrum JT, Bone RA. Lutein, zeaxanthin, and the macular pigment. Arch Biochem Biophys.

501

502

503

504

505

506

507

508

509 
27. Borel P, Moussa M, Reboul E, Lyan B, Defoort C, Vincent-Baudry S, et al. Human fasting plasma concentrations of vitamin $\mathrm{E}$ and carotenoids, and their association with genetic variants in apo C-III, cholesteryl ester transfer protein, hepatic lipase, intestinal fatty acid binding protein and microsomal triacylglycerol transfer protein. Br J Nutr. 2008 Jul 29:1-8.

28. During A, Doraiswamy S, Harrison EH. Xanthophylls are preferentially taken up compared with betacarotene by retinal cells via a SRBI-dependent mechanism. J Lipid Res. 2008 Aug;49(8):1715-24.

29. von Lintig J, Vogt K. Vitamin A formation in animals: molecular identification and functional characterization of carotene cleaving enzymes. J Nutr. 2004 Jan;134(1):251S-6S.

30. Vage DI, Boman IA. A nonsense mutation in the beta-carotene oxygenase 2 (BCO2) gene is tightly associated with accumulation of carotenoids in adipose tissue in sheep (Ovis aries). BMC Genet.11:10.

31. Hercberg S, Deheeger M, Preziosi P. SU.VI.MAX: Portions alimentaires. Manuel photos pour l'estimation des quantités. 1994;Su.Vi.Max.-Candia-Polytechnica.

32. Chug-Ahuja JK, Holden JM, Forman MR, Mangels AR, Beecher GR, Lanza E. The development and application of a carotenoid database for fruits, vegetables, and selected multicomponent foods. J Am Diet Assoc. 1993;93(3):318-23.

33. Cardinault N, Tyssandier V, Grolier P, Winklhofer-Roob BM, Ribalta J, Bouteloup-Demange C, et al. Comparison of the postprandial chylomicron carotenoid responses in young and older subjects. Eur J Nutr. 2003 Dec;42(6):315-23.

34. Tyssandier V, Feillet-Coudray C, Caris-Veyrat C, Guilland JC, Coudray C, Bureau S, et al. Effect of tomato product consumption on the plasma status of antioxidant microconstituents and on the plasma total antioxidant capacity in healthy subjects. J Am Coll Nutr. 2004 Apr;23(2):148-56.

35. Caris-Veyrat C, Amiot MJ, Tyssandier V, Grasselly D, Buret M, Mikolajczak M, et al. Influence of organic versus conventional agricultural practice on the antioxidant microconstituent content of tomatoes and derived purees; consequences on antioxidant plasma status in humans. J Agric Food Chem. 2004 Oct 20;52(21):6503-9.

36. Curran-Celentano J, Hammond BR, Jr., Ciulla TA, Cooper DA, Pratt LM, Danis RB. Relation between dietary intake, serum concentrations, and retinal concentrations of lutein and zeaxanthin in adults in a Midwest population. Am J Clin Nutr. 2001;74(6):796-802.

37. De la Vega FM, Lazaruk KD, Rhodes MD, Wenz MH. Assessment of two flexible and compatible SNP genotyping platforms: TaqMan SNP Genotyping Assays and the SNPlex Genotyping System. Mutat Res. 2005 Jun 3;573(1-2):111-35.

38. Tobler AR, Short S, Andersen MR, Paner TM, Briggs JC, Lambert SM, et al. The SNPlex genotyping system: a flexible and scalable platform for SNP genotyping. J Biomol Tech. 2005 Dec;16(4):398-406.

39. Zagers NPA, van Norren D. Absorption of the eye lens and macular pigment derived from the reflectance of cone photoreceptors. J Opt Soc Am. 2004;21:2257-68

40. van de Kraats J, van Norren D. Directional and nondirectional spectral reflection from the human fovea J Biomed Opt. 2008;13(2):024010.

41. Lyan B, Azais-Braesco V, Cardinault N, Tyssandier V, Borel P, Alexandre-Gouabau MC, et al. Simple method for clinical determination of 13 carotenoids in human plasma using an isocratic high-performance liquid chromatographic method. J Chromatogr B Biomed Appl. 2001;751(2):297-303.

42. Hercberg S, Galan P, Preziosi P, Bertrais S, Mennen L, Malvy D, et al. The SU.VI.MAX Study: a randomized, placebo-controlled trial of the health effects of antioxidant vitamins and minerals. Arch Intern Med. 2004 Nov 22;164(21):2335-42.

43. Tregouet DA, Escolano S, Tiret L, Mallet A, Golmard JL. A new algorithm for haplotype-based association analysis: the Stochastic-EM algorithm. Ann Hum Genet. 2004 Mar;68(Pt 2):165-77.

44. Johnson EJ, Chung HY, Caldarella SM, Snodderly DM. The influence of supplemental lutein and docosahexaenoic acid on serum, lipoproteins, and macular pigmentation. Am J Clin Nutr. 2008 May;87(5):1521-9.

45. Richer S, Stiles W, Statkute L, Pulido J, Frankowski J, Rudy D, et al. Double-masked, placebo-controlled, randomized trial of lutein and antioxidant supplementation in the intervention of atrophic age-related macular degeneration: the Veterans LAST study (Lutein Antioxidant Supplementation Trial). Optometry. 2004 Apr;75(4):216-30.

46. Bone RA, Landrum JT, Guerra LH, Ruiz CA. Lutein and Zeaxanthin Dietary Supplements Raise Macular Pigment Density and Serum Concentrations of these Carotenoids in Humans. J Nutr. 2003;133(4):992-8.

47. Riso P, Brusamolino A, Ciappellano S, Porrini M. Comparison of lutein bioavailability from vegetables and supplement. Int J Vitam Nutr Res. 2003 May;73(3):201-5.

48. Chung HY, Rasmussen HM, Johnson EJ. Lutein bioavailability is higher from lutein-enriched eggs than from supplements and spinach in men. J Nutr. 2004 Aug;134(8):1887-93. 
49. Cardinault N, Gorrand JM, Tyssandier V, Grolier P, Rock E, Borel P. Short-term supplementation with lutein affects biomarkers of lutein status similarly in young and elderly subjects. Exp Gerontol. 2003 May;38(5):573-82.

50. Broekmans WM, Berendschot TT, Klopping-Ketelaars IA, de Vries AJ, Goldbohm RA, Tijburg LB, et al. Macular pigment density in relation to serum and adipose tissue concentrations of lutein and serum concentrations of zeaxanthin. Am J Clin Nutr. 2002;76(3):595-603.

51. Johnson EJ, Hammond BR, Yeum KJ, Qin J, Wang XD, Castaneda C, et al. Relation among serum and tissue concentrations of lutein and zeaxanthin and macular pigment density. Am J Clin Nutr. 2000;71(6):1555-62.

52. Bone RA, Landrum JT, Dixon Z, Chen Y, Llerena CM. Lutein and zeaxanthin in the eyes, serum and diet of human subjects. Exp Eye Res. 2000 Sep;71(3):239-45.

53. Richer S, Devenport J, Lang JC. LAST II: Differential temporal responses of macular pigment optical density in patients with atrophic age-related macular degeneration to dietary supplementation with xanthophylls. Optometry. 2007 May;78(5):213-9.

54. Ferrucci L, Perry JR, Matteini A, Perola M, Tanaka T, Silander K, et al. Common Variation in the betaCarotene 15,15'-Monooxygenase 1 Gene Affects Circulating Levels of Carotenoids: A Genome-Wide Association Study. Am J Hum Genet. 2009 Jan 28.

55. Grolier P, Duszka C, Borel P, Alexandre-Gouabau MC, Azais-Braesco V. In vitro and in vivo inhibition of beta-carotene dioxygenase activity by canthaxanthin in rat intestine. Arch Biochem Biophys. $1997 ; 348(2): 233-8$.

56. Langmann T, Liebisch G, Moehle C, Schifferer R, Dayoub R, Heiduczek S, et al. Gene expression profiling identifies retinoids as potent inducers of macrophage lipid efflux. Biochim Biophys Acta. 2005;1740:15561.

57. Leung WC, Hessel S, Meplan C, Flint J, Oberhauser V, Tourniaire F, et al. Two common single nucleotide polymorphisms in the gene encoding \{beta\}-carotene 15,15'-monoxygenase alter \{beta\}-carotene metabolism in female volunteers. FASEB J. 2008 Dec 22.

58. West M, Greason E, Kolmakova A, Jahangiri A, Asztalos B, Pollin TI, et al. Scavenger receptor class B type I protein as an independent predictor of high-density lipoprotein cholesterol levels in subjects with hyperalphalipoproteinemia. J Clin Endocrinol Metab. 2009 Apr;94(4):1451-7.

59. Constantineau J, Greason E, West M, Filbin M, Kieft JS, Carletti MZ, et al. A synonymous variant in scavenger receptor, class B, type I gene is associated with lower SR-BI protein expression and function. Atherosclerosis. 2010;210:177-82. 

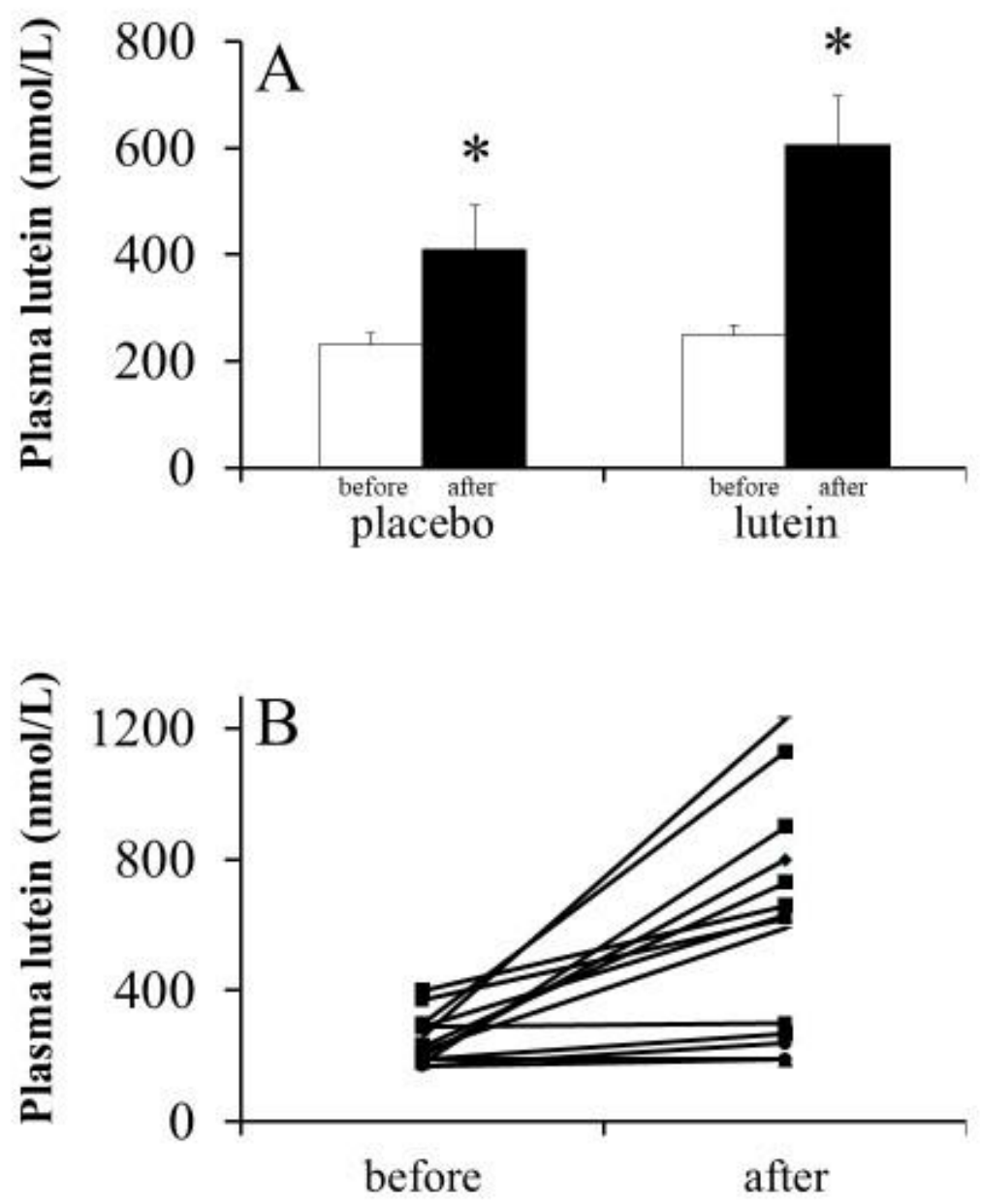

Figure 1

Figure 1: (A) Plasma lutein concentrations, before and after supplementation, in both the group that took the placebo and the group that took the lutein supplement. White bars: values measured before supplementation. Black bars: values measured after supplementation. Means \pm SEM of 15 subjects in placebo group and 14 subjects in lutein group. An asterisk indicates a significant difference $(P<0.05)$ between values measured before and after the supplementation period in each group (paired t test). (B) Individual plasma lutein concentrations, before and after supplementation, in the placebo group. (C) Individual plasma lutein concentrations, before and after supplementation, in the lutein supplemented group. 

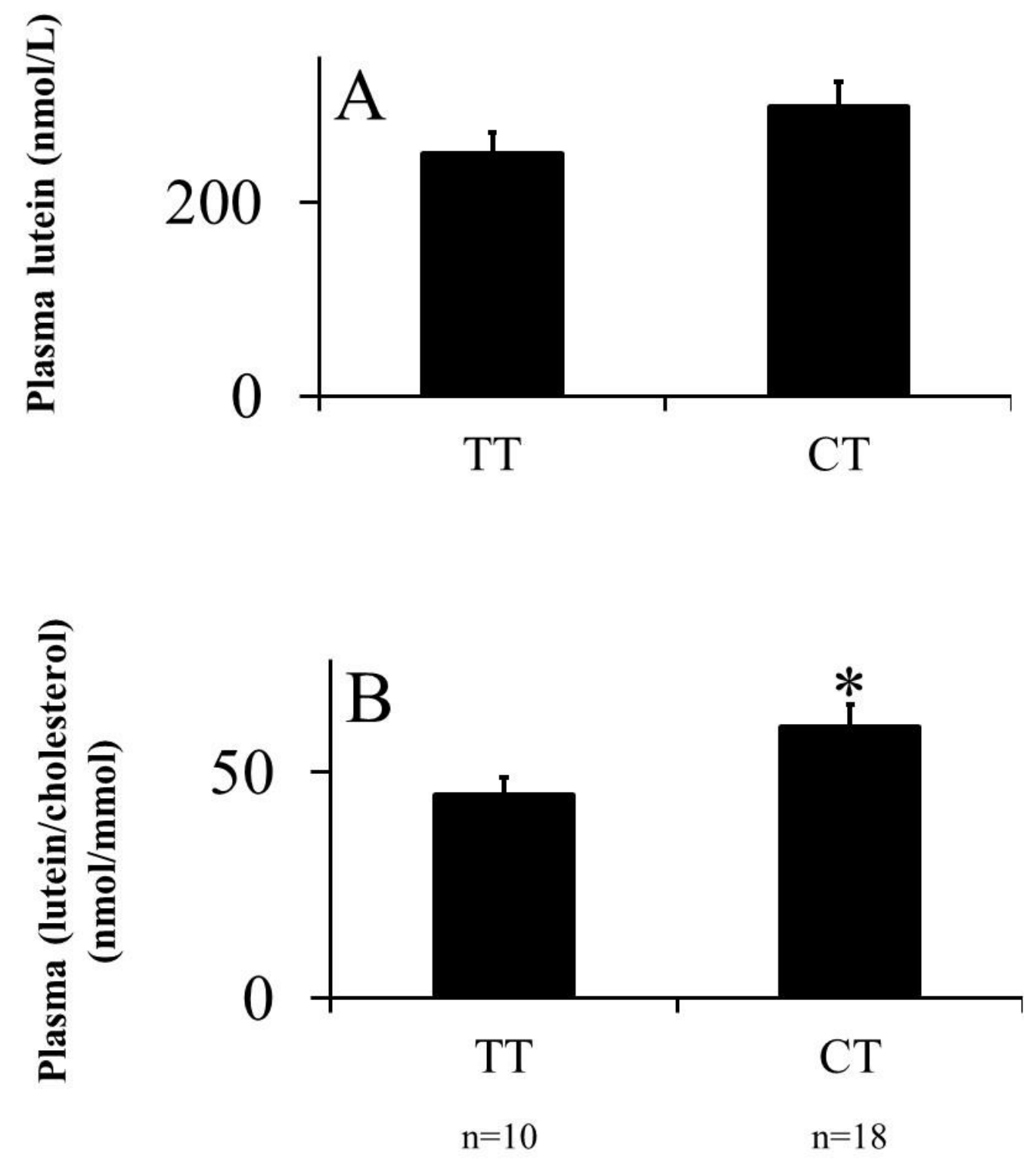

671

672 673 674 675 676 677 678 679 680 681 682 683 684 685 686 687 688 689 690 691
Figure 2: Baseline plasma lutein concentrations for each BCMO1 rs7501331 genotype. (A) uncorrected values. (B) values corrected for plasma total cholesterol. Data are means \pm SEM of 28 subjects. $n$ is the number of subject in each genotype group. An asterisk indicates a significant difference $(P<0.05)$ between genotype groups (Student's t test). 

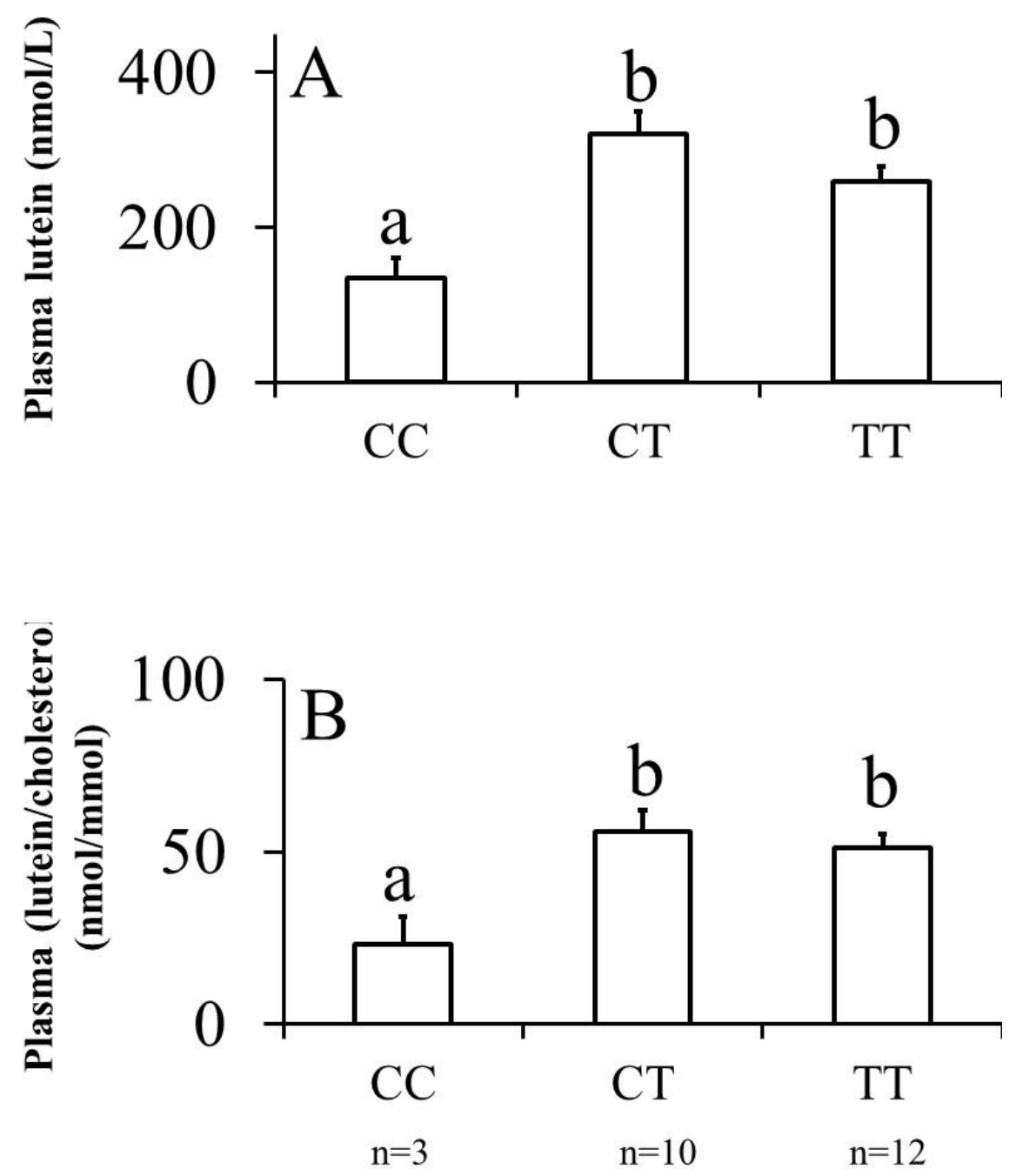

692 Figure 3: Baseline plasma lutein concentrations for each CD36 rs13230419 genotype. (A) uncorrected values. 693 (B) Values corrected for plasma total cholesterol. Data are means \pm SEM of 25 subjects. $n$ is the number of 694 subject in each genotype group. In each figure, different letters indicate significant differences $(P<0.05)$ 695 between genotype groups (ANOVA). 

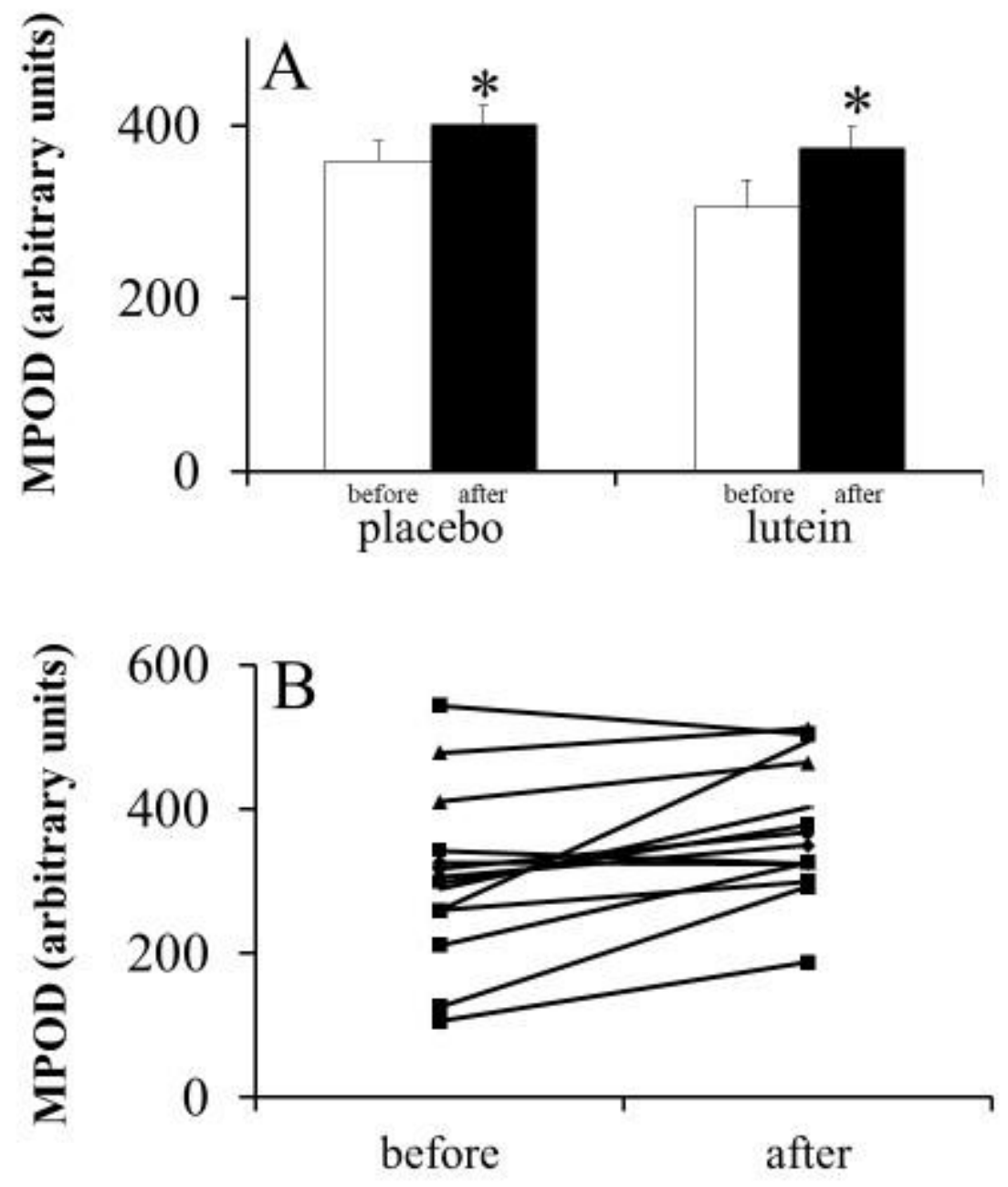

Figure 4

Figure 4: (A) MPOD (macular pigment optical density), before and after supplementation, in the group that took the placebo and the group that took the lutein supplement. White bars: values measured before supplementation (before). Black bars: values measured after supplementation (after). Means \pm SEM of 15 subjects in placebo group and 14 subjects in lutein group. An asterisk indicates a significant difference $(P<0.05)$ between values measured before and after the supplementation period in each group (paired $t$ test). (B) Individual MPOD before and after supplementation in the lutein supplemented group $(\mathrm{n}=14)$. 

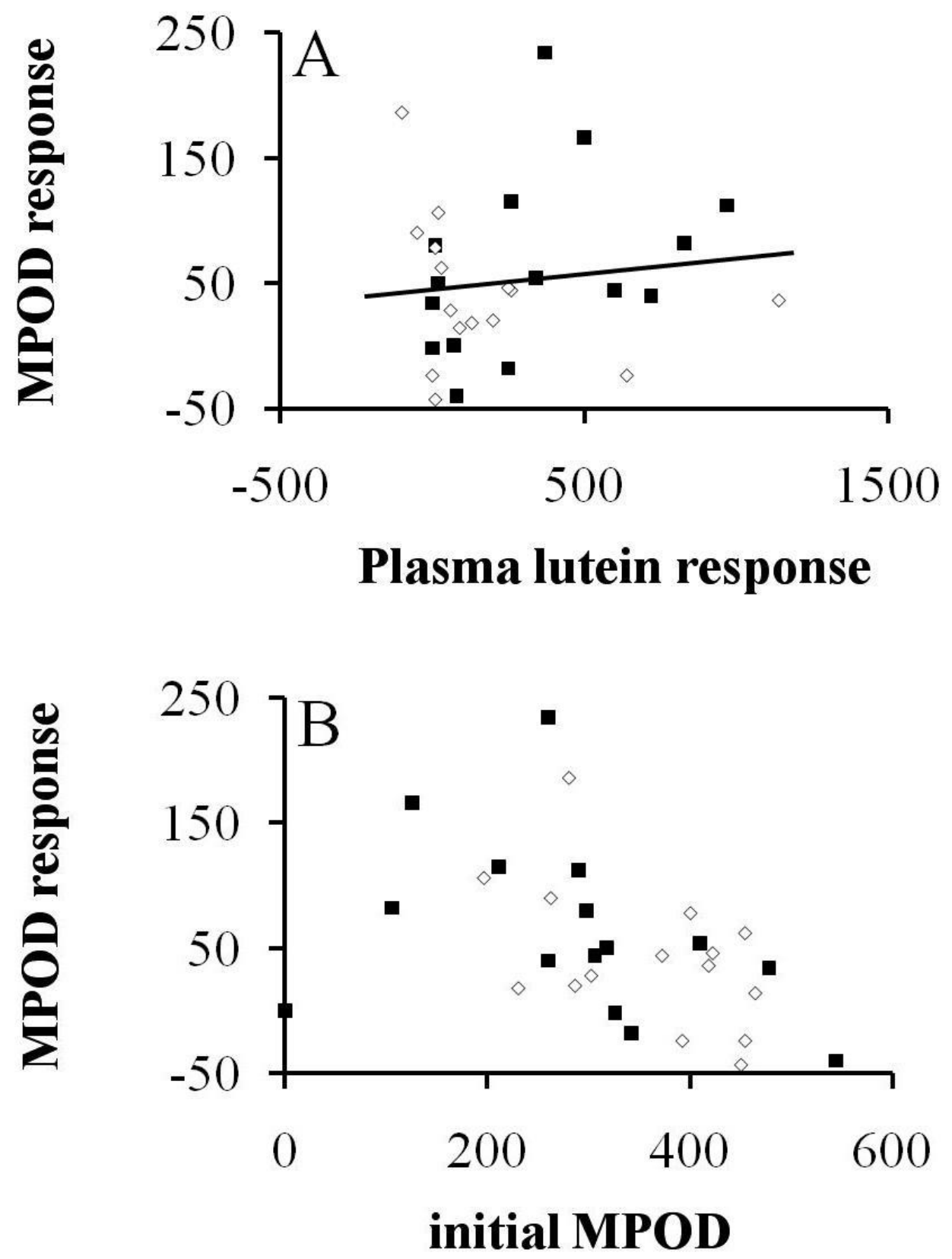

Figure 5: (A) MPOD response as a function of plasma lutein response. (B) MPOD response as a function of initial MPOD. "Response" indicates the differences between the values measured after the dietary intervention and the values measured before the intervention $(n=29)$. White dots: subjects in the placebo group, black dots: subjects in the lutein supplemented group. 

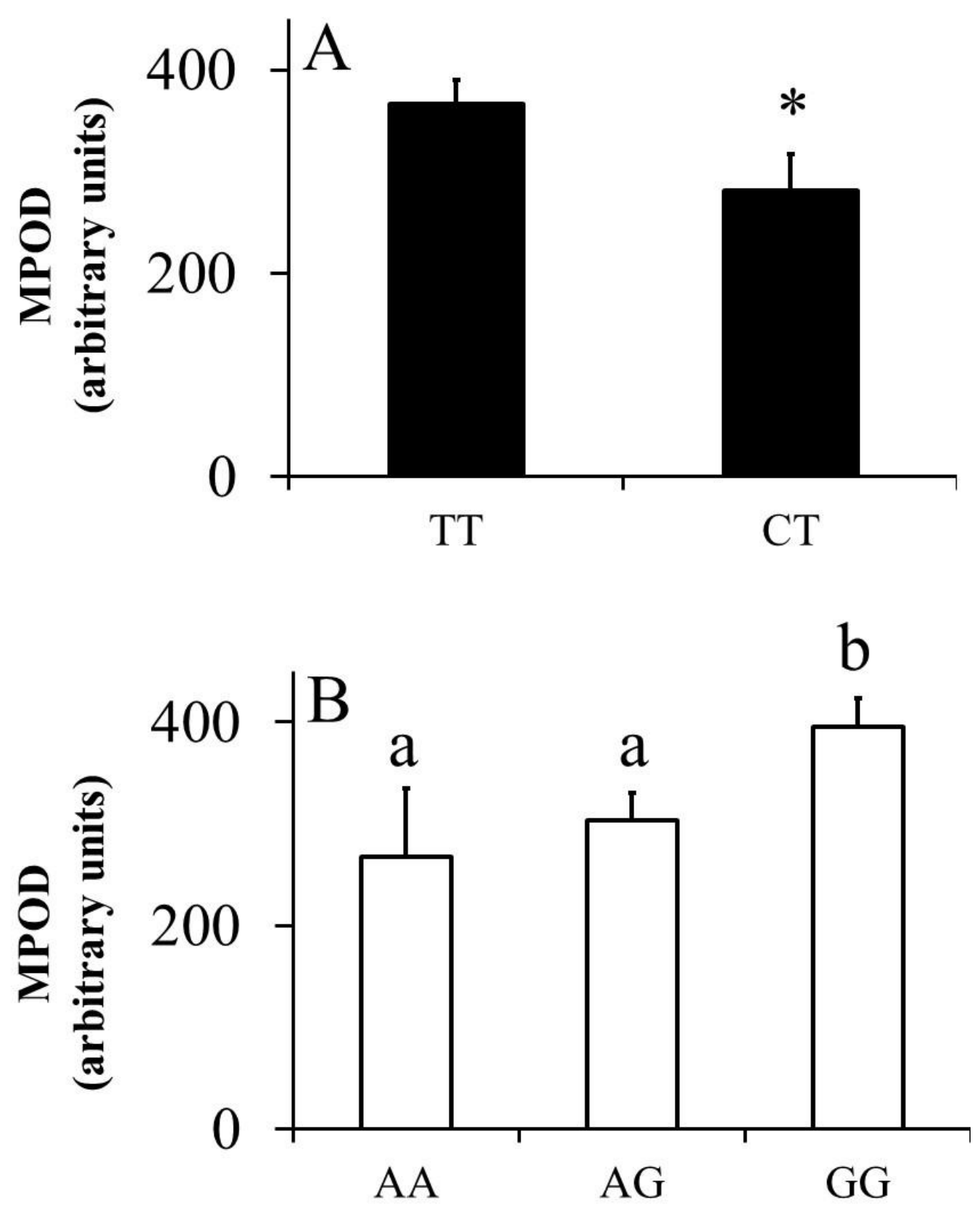

Figure 6: MPOD for each BCMO1 and CD36 genotype. (A) BCMO1 rs7501331 genotypes. An asterisk 
758 Table 1 Characteristics and nutrient intake of the 29 male subjects enrolled in the clinical study ${ }^{1}$

\begin{tabular}{lc}
\hline Item & Mean \pm SD \\
\hline Age, $y$ & $49.7 \pm 0.8$ \\
Height, $\mathrm{cm}$ & $174.2 \pm 1.2$ \\
Weight, $\mathrm{kg}$ & $71.1 \pm 1.3$ \\
Plasma analytes & \\
Glucose, $\mathrm{mmol} / \mathrm{L}$ & $4.88 \pm 0.09$ \\
Triglycerides, $\mathrm{mmol} / \mathrm{L}$ & $0.93 \pm 0.07$ \\
Total cholesterol, $\mathrm{mmol} / \mathrm{L}$ & $4.91 \pm 0.14$ \\
HDL cholesterol, $\mathrm{mmol} / \mathrm{L}$ & $1.63 \pm 0.08$ \\
LDL cholesterol, $\mathrm{mmol} / \mathrm{L}$ & $2.99 \pm 0.13$ \\
Nutrient intake & \\
Total Energy, $\mathrm{kJ} / \mathrm{d}$ & \\
Alcohol, $g / d$ & $2406 \pm 103$ \\
Carbohydrate, $g / d$ & $9.0 \pm 2.2$ \\
Protein, $g / d$ & $279.1 \pm 14.2$ \\
Fat, $g / d$ & $94.2 \pm 4.4$ \\
Lutein+zeaxanthin $m g / d$ & $98.0 \pm 4.9$ \\
\hline
\end{tabular}

$760{ }^{1}$ Nutrient intake of the subjects as evaluated, at the begginning of the study (i.e. before the lutein-poor diet), by a 761 3-day food diary. 
Table 2 Characteristics of the studied SNPs

\begin{tabular}{|c|c|c|c|c|c|c|c|}
\hline Gene & dbSNP ID & SNP ID & $\begin{array}{l}\text { Main } \\
\text { allele }\end{array}$ & $\begin{array}{l}\text { Minor } \\
\text { llele }\end{array}$ & $\begin{array}{l}\text { MAF } \\
(\%)^{1}\end{array}$ & $\begin{array}{c}\text { Intron (I)/Exon } \\
\text { (E)/N(Near the gene) }\end{array}$ & $\begin{array}{c}\text { Possible effect on } \\
\text { protein } \\
\text { activity/expression }\end{array}$ \\
\hline ABCA1 & rs2230808 & hCV2741104 & $\mathrm{G}$ & $\mathrm{A}$ & 24.3 & $\mathrm{E}$ & $\mathrm{NS}^{2}$ \\
\hline ABCA1 & rs2066718 & hCV11720789 & G & $\mathrm{A}$ & 3.5 & $\mathrm{E}$ & NS \\
\hline ABCA1 & rs2230806 & hCV2741051 & G & $\mathrm{A}$ & 28.8 & $\mathrm{E}$ & NS \\
\hline ABCA1 & rs2230805 & hCV2741050 & $\mathrm{G}$ & $\mathrm{A}$ & 27.4 & $\mathrm{E}$ & silent \\
\hline ABCG5 & rs6720173 & hCV29001998 & G & $\mathrm{C}$ & 15.2 & $\mathrm{E}$ & NS \\
\hline ABCG8 & rs4148211 & hCV29535502 & A & $\mathrm{G}$ & 35.0 & $\mathrm{E}$ & NS \\
\hline ABCG8 & rs4148217 & hCV375061 & $\mathrm{C}$ & $\mathrm{A}$ & 20.2 & $\mathrm{E}$ & NS \\
\hline ABCG8 & rs6544718 & hCV25642779 & $\mathrm{C}$ & $\mathrm{T}$ & 20.5 & $\mathrm{E}$ & NS \\
\hline $\mathrm{BCDO} 2$ & rs7123686 & hCV22274763 & A & $\mathrm{C}$ & 33.6 & I & - \\
\hline BCMO1 & rs12934922 & hCV25745282 & A & $\mathrm{T}$ & 45.7 & $\mathrm{E}$ & NS \\
\hline BCMO1 & rs7501331 & $\mathrm{hCV}^{3}$ & $\mathrm{~T}$ & $\mathrm{C}$ & 23.6 & E & NS \\
\hline CD36 & rs1527483 & hCV8315330 & $\mathrm{C}$ & $\mathrm{T}$ & 8.0 & I & - \\
\hline CD36 & rs1761667 & hCV8314499 & A & $\mathrm{G}$ & 45.1 & $\mathrm{~N}$ & $?$ \\
\hline CD36 & rs13230419 & hCV1803768 & $\mathrm{T}$ & $\mathrm{C}$ & 44.0 & $\mathrm{~N}$ & $?$ \\
\hline CD36 & rs7755 & hCV8315318 & $\mathrm{G}$ & $\mathrm{A}$ & 43.9 & $\mathrm{~N}$ & $?$ \\
\hline CD36 & rs1984112 & hCV12093946 & A & $\mathrm{G}$ & 35.8 & $\mathrm{~N}$ & $?$ \\
\hline NPC1L1 & rs217434 & hCV2292875 & A & $\mathrm{G}$ & 18.2 & $\mathrm{E}$ & silent \\
\hline NPC1L1 & rs217428 & hCV29736499 & $\mathrm{T}$ & $\mathrm{G}$ & 24.1 & I & - \\
\hline NPC1L1 & rs17655652 & hCV2625150 & $\mathrm{T}$ & $\mathrm{C}$ & 31.8 & $\mathrm{~N}$ & $?$ \\
\hline SCARB1 & rs5888 & hCV7497008 & $\mathrm{C}$ & $\mathrm{T}$ & 47.2 & $\mathrm{E}$ & silent \\
\hline SCARB1 & rs4238001 & hCV26062113 & $\mathrm{C}$ & $\mathrm{T}$ & 13.0 & $\mathrm{E}$ & NS \\
\hline SCARB1 & intron $5^{3}$ & hCV25608758 & $\mathrm{C}$ & $\mathrm{T}$ & 10.0 & I & - \\
\hline
\end{tabular}

765

766

767

768

769

770

771

772

773

774

775

776

${ }^{1}$ MAF: minor allele frequency as observed in a cohort of 2994 french subjects which was a subset of the french SUVIMAX cohort (42). ${ }^{2} \mathrm{NS}$ : non synonymous SNP (missense), indicating a change of amino acid. ${ }^{3}$ not referenced in SNP ID or dbSNP. ?: effect not known, although it may have a possible effect on gene expression.

SNPs were genotyped with the SNPlex assay except hCV26062113 and hCV25608758, which were genotyped by Taqman (see Materials and methods). 
778 Table 3 BCMO1 haplotypes effects on plasma lutein/zeaxanthin

779

780

Haplotypes

\begin{tabular}{cccc}
\hline rs12934922 & rs7501331 & $\begin{array}{c}\text { Frequencies }^{\mathbf{1}} \\
(\boldsymbol{\%})\end{array}$ & ${\text { Haplotype } \text { effect }^{2}}$ \\
\hline $\mathrm{A}$ & & 34.1 & \\
$\mathrm{~A}$ & $\mathrm{C}$ & 21.1 & 0.571 \\
$\mathrm{~T}$ & $\mathrm{~T}$ & 42.7 & 0.887 \\
$\mathrm{~T}$ & $\mathrm{C}$ & 2.1 & - \\
& $\mathrm{T}$ & & 0.368 \\
\hline
\end{tabular}

781

782 Plasma lutein/zeaxanthin and BCMO1 SNPs were assessed in 622 french subjects (281 males, 341 females).

$783{ }^{1}$ Haplotype frequencies were estimated using Thesias software (43). The most frequent haplotype (TC) is the

784 reference haplotype. ${ }^{2}$ Haplotype effect on plasma lutein/zeaxanthin by comparison to the most frequent

785 haplotype ( $\mathrm{p}$ value calculated by Student $\mathrm{t}$-test).

786

787 
Table 4 CD36 haplotypes effects on plasma lutein/zeaxanthin

789

\begin{tabular}{ccccc}
\hline rs1984112 & rs1761667 & rs7755 & $\begin{array}{c}\text { Haplotype } \\
\text { Frequencies }\end{array}$ & Haplotype effect $^{{ }^{2}}$ \\
& & & $(\%)$ & \\
\hline A & A & A & 10.2 & 0.992 \\
A & A & G & 45.2 & - \\
A & G & A & 8.4 & 0.018 \\
A & G & G & 1.9 & 0.567 \\
G & A & G & 0.1 & -3 \\
G & G & A & 26.2 & 0.908 \\
G & G & G & 7.9 & 0.074 \\
\hline
\end{tabular}

790

791 Plasma lutein/zeaxanthin and CD36 SNPs were assessed in 622 french subjects (281 males, 341 females).

$792{ }^{1}$ Haplotype frequencies were estimated using Thesias software (43). The most frequent haplotype (AAG) is the

793 reference haplotype. ${ }^{2}$ Haplotype effect on plasma lutein/zeaxanthin by comparison to the most frequent

794 haplotype ( $\mathrm{p}$ value calculated by Student $\mathrm{t}$-test). ${ }^{3}$ could not be calculated because of the too low frequency of this

795 haplotype. 


\section{Acknowledgement}

798

799 Financial support: Work on the cohort of 29 subjects was funded by Pileje. Pileje participated

800 in the design of the study and approval of the manuscript. Work on the subset cohort of

801 SUVIMAX was granted by ANR ( ${ }^{\circ}$ ANR-05-PNRA-010), DGS (Ministry of Health) and

802 supported by Médéric, Ipsen, MGEN, SODEXHO and Pierre Fabre. None of these

803 organisations or companies participated in the design or conducted of this research.

804

805 Authors with financial/conflict of interest: Stéphanie Baudry, Sophie Drouault-Holowacz, 806 Severine Bieuvelet.

807

808

809 